\title{
The unresponsive EEGs of college underachievers
}

BRENNA H. BRY AND ROBERT S. DANIEL 2 UNIVERSITY OF MISSOURI AT COLUMBIA

The EEGs of college achievers and ability-matched underachievers were recorded under conditions of eyes closed, eyes opened, and during a mental arithmetic task. Computer quantification of the recordings showed no group differences for eyes closed. In the other two conditions achievers had normal EEG arousal patterns whereas underachievers did not.

Academic underachievers are typically described as difficult to motivate, emotionally inhibited, under-reactive, and nonattentive (Heath, 1964). These characteristics suggest a low state of arousal, but few researchers have studied any physiological correlates of underachievement. Among the possible variables, the electroencephalogram (EEG) is becoming more useful as a psychophysiological indicator of arousal level by application of new computer techniques to data. Quantifications of autocorrelograms (in the form of ratios) from EEG epochs have been developed and validated by Daniel $(1964,1965)$ for this purpose.

The present study was designed to determine EEG arousal levels in a group of underachievers as compared to a group of matched achievers under conditions of eyes closed, eyes opened, and in an academic-like task. Method

The 10 most extreme underachievers (Us) among the 19-20 year old, male, sophomore, Arts College students on campus were chosen as Ss. Their mean grade point average (GPA) was 1.2 on a 4.0 system $(\mathrm{SD}=.42)$. All Us had a GPA of at least one SD (.90) below their expected GPA based upon the School and College Abilities Test (SCAT) and local norms (Prediger, Krauskopf, \& Callis, 1963). This criterion is similar to that used in other studies of college underachievers (Farquhar \& Payne, 1964).

A control group of achieving students (As) was selected on a matched-pair basis. Criteria used for matching were, in order of importance: (a) total SCAT score; (b) SCAT verbal and quantitative subtest scores; and (c) size of high school. All As were also male sophomores in the Arts College with an age of 19-20. Matching was virtually perfect for criteria (a) and (b) and was approximate for (c). Achievers' mean GPA was 3.1 (SD $=.47$ ) in comparison to a predicted GPA of 2.6 (for each group). The two groups differed not only in GPA but also in that the Us were all underachievers in high school whereas none of the As were, Us accumulated more class cuts the previous semester (Us' $\bar{X}=31, A s^{\prime} \bar{X}=3$ ), and more Us (six) than As (none) were fraternity members. All Ss were paid for participation.

The experiment was run in two sessions. On Day 1, all Ss were familiarized with the equipment and recording procedure, and taught the experimental task. A modi- fled level of aspiration (LOA) paradigm was used with "mental" arithmetic operations. A S began each trial with the integer 1, and pressed one or more of four avallable response keys labeled $1,2,3$, and 4 to indicate which of these four digits could be divided evenly into the number he had in mind. $S$ used successive integers as numerators in division problems, completting as many as possible in the time allowed. Thus, each time $S$ pressed Key 1, he indicated to $E$ that he was working on the next problem, and subsequent responses on the remaining keys indicated his solution. It is apparent that correct responses would be $1,1-2,1-3,1-2-4,1$, 1-2-3, etc. After one 30-sec trial, $S$ was told the mean score of students (derived from pilot work) and asked to predict his own score on the next trial. Six additional practice trials were given with Spredicting performance on each trial, but with E surreptitiously manipulating the trial duration slightly in order to give every $S$ the same pattern of successes and failures. $S$ was told practice trials would be $1,1,2,2,3$, and $3 \mathrm{~min}$ for the six trials of this session.

On Day 2, one week later, Ss were requested to relax for a base-state, eyes closed EEG recording (1.5 min) followed by an eyes opened recording (1.5 min) and a continuous recording during one 3-min trial on the LOA task with eyes closed. The room was in darkness throughout the session. Simultaneous graphic (Offiner Type R dynograph) and magnetic tape (Ampex FR 1100) recordings were made from four scalp electrodes, but data from only the left occipital-to-vertex pair were utilized in the analysis. EEG epochs chosen for analysis were 1-min artifact-free segments for each $S$ under each of the three conditions ( $30 \mathrm{sec}$ after the start of mental work).

A special purpose computer was used for data reduction and quantification by the method of autocorrelation. The system has a capacity for 98 delay steps (beyond zero delay) of $8 \mathrm{msec}$ each or a total scan of $784 \mathrm{msec}$. Normallzed correlograms were plotted and further reduced to correlogram ratios according to the method described by Daniel (1964). These ratios have been shown to reflect behavioral differences in arousal (Daniel, 1965). Alpha frequency and total power values were taken from the correlograms and computer readout, respectively.

Results

Figure 1 shows the principal results of the study. Correlogram ratios are plotted by experimental group and treatment. For Us, there is little or no increase in arousal (reduced ratio) in going from eyes closed to eyes opened to mental work. For As there is a sharp increase in arousal upon opening the eyes (even in dark- 


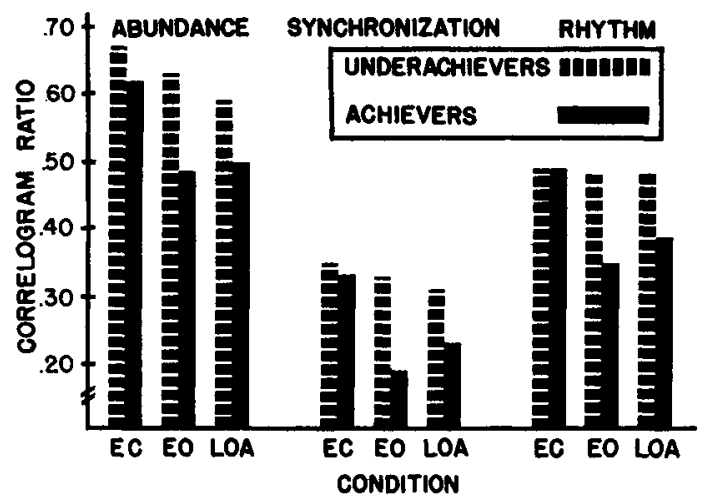

Fig. 1. Mean correlogram ratios by experimental group and condition. EC=eyes closed, EO=eyes opened, $\mathrm{LOA}=$ level of aspiration task. The smaller the ratio the greater is the arousal.

ness) followed by less, but still appreciable, arousal when they close their eyes and do mental work. The pattern holds for all three ratios.

Significance of differences across groups and conditions was checked by the Wilcoxon matched-pairs signed-ranks test (Siegel, 1956). Achievers are more aroused by opening the eyes than are Us on all three ratios $(p<.05)$. Differences for As between eyes closed and eyes opened are significant ( $p<.025$ or better) on all three ratios, but for the Us only the Abundance Ratio is significant $(p<.025)$. Likewise, the differences for As between eyes closed and mental work are significant ( $p<.05$ or better) on all three ratios, but for the Us only the Abundance Ratio is significant $(p<.025)$. No other group or condition difference reached significance.

Dominant EEG frequency (alpha) was greater for Us $(9.79 \mathrm{~Hz})$ than As $(9.30 \mathrm{~Hz})$ during eyes closed $(p<.05)$ and significant differences were maintained throughout the experiment. A slowing by approximately .2 Hz occurred for the As during the eyes opened condition but during mental work frequency returned to the eyes closed level. Underachievers' alpha frequency did not change for any condition. Group differences in total EEG power were not observed.

\section{Discussion}

By EEG indices, academic underachievers were aroused scarcely at all under the normally motivating tasks employed in this study. In striking contrast, the achievers showed clear evidence of behaving at a higher arousal level when motivated. If evidence were presented for the mental arithmetic task alone, one might suppose that the results merely reflected the fact the underachievers are not interested in intellectual tasks. However, an even more striking and convincing difference between the groups was obtained by having them open their eyes in darkness. It has long been known that instructed expectation for seeing or not seeing will modify the typical alpha desynchronization obtained uponopening the eyes (Loomis et al, 1936). Thus the present results contain a suggestion of a fundamental biologic or firmly habituated pattern of nonresponsivity in the underachiever. Ellingson (1956) and more recently Walters (1964) have reviewed studies on "persistent alpha" subjects, pointing out personality characteristics similar to those commonly ascribed to underachievers.

There are also some implications in these results concerning the nature of alpha desynchronization with stimulation. Since achievers showed arousal by all three ratios, desynchronization for them is a loss of alpha power (abundance ratio), a loss of wave-to-wave alpha persistence (synchronization ratio), and a loss of waveto-wave alpha pattern similarity (rhythm ratio). In terms of graphic EEG tracings, this means that the alpha is reduced in amplitude (modulated), has become fragmented (low index), and is less constant in form. In contrast, the two stimulating conditions for the underachievers produced the amplitude reduction, a nonsignificant tendency toward the fragmentation, and no tendency toward loss of uniformity. Multidimensional analyses of the EEG are proving superior to single parameter studies, but it must be remembered that such approaches involve possible interdependencies. For example, abundance, synchronization, and rhythm are not necessarily isolated characteristics.

\section{References}

DANIEL, R. S. Electroencephalographic correlogram ratios and their stability. Science, 1964, 145, 721-723.

DANIEL, R. S. Electroencephalographic pattern quantification and the arousal continuum. Psychophysiology, 1965, 2, 146-160.

ELLINGSON, R. J. Brain waves and problems in psychology. Psychol. Bull., 1956, 53, 1-34.

FARQUHAR, W. W., \& PAYNE, D. A. A classification and comparison of techniques used in selecting under- and over-achievers. Personnel Guid. J., 1964, 42, 874-884.

HEATH, R. The reasonable adventurer. Pittsburgh: University of Pittsburgh Press, 1964.

LOOMIS, A. L., HARVEY, E. N., \& HOBART, G. Electrical potentials of the human brain. $J$. exp. Psychol, 1936, 19, 249-279.

PREDIGER, D. J., KRAUSKOPF, C. J., \& CALLIS, R. Predicting academic success at the University of Missouri. Testing and Counseling Service Report, Jan., 1963, 17, No. 3.

SIEGEL, S. Nonparametric statistics for the behavioral sciences. New York: McGraw-Hill, 1956.

WALTERS, CATHRYN. Clinical and experimental relationships of EEG to psychomotor and personality measures. J. clin. Psychol., 1964, 20, 81-91.

\section{Notes}

1. Supported in part by USPHS grant 10936 and by a NASA traineeship to the first author. We are indebted to Mr. James Jennings for aid in computer processing of data and to Dean Thomas B. Harris and Professor C. J. Krauskopf for cooperation in identifying our underachiever Ss. 2. Adapted from a thesis submitted to the Graduate School in partial fulfillment of the MA degree by the first author under the direction of the second author. 